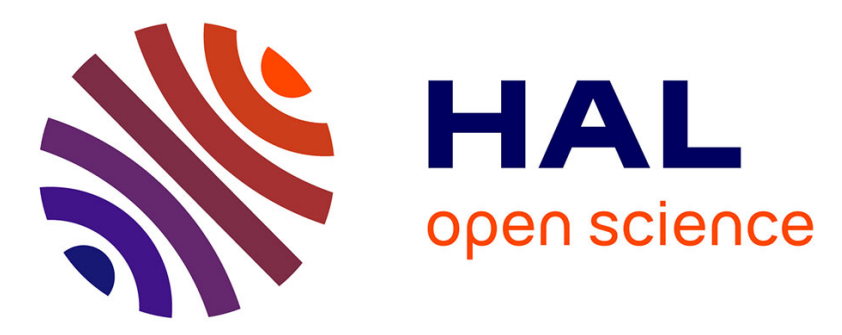

\title{
Estimating Leaf Carotenoid Concentration of Ginger in Different Layers Based on Discrete Wavelet Transform Algorithm
}

Qinhong Liao

\section{- To cite this version:}

Qinhong Liao. Estimating Leaf Carotenoid Concentration of Ginger in Different Layers Based on Discrete Wavelet Transform Algorithm. 11th International Conference on Computer and Computing Technologies in Agriculture (CCTA), Aug 2017, Jilin, China. pp.152-158, 10.1007/978-3-030-061371_16. hal-02124260

\author{
HAL Id: hal-02124260 \\ https://hal.inria.fr/hal-02124260
}

Submitted on 9 May 2019

HAL is a multi-disciplinary open access archive for the deposit and dissemination of scientific research documents, whether they are published or not. The documents may come from teaching and research institutions in France or abroad, or from public or private research centers.
L'archive ouverte pluridisciplinaire HAL, est destinée au dépôt et à la diffusion de documents scientifiques de niveau recherche, publiés ou non, émanant des établissements d'enseignement et de recherche français ou étrangers, des laboratoires publics ou privés.

\section{(c)(1)}

Distributed under a Creative Commons Attribution| 4.0 International License 


\title{
Estimating Leaf Carotenoid Concentration of Ginger in Different Layers Based on Discrete Wavelet Transform Algorithm
}

\author{
Qinhong Liao ${ }^{(凶)}$ \\ Research Institution for Special Plants, Chongqing University of Art and Science, \\ Chongqing, China \\ lqhwisdom@126.com
}

\begin{abstract}
Ginger is one of the very important industrial crops in southwest, China. Accurate estimation of its leaf carotenoid concentration (LCC) is important to assess ginger photosynthetic capacity and direct the precision agriculture management. This study focused on introducing a new approach for estimating the LCC of ginger leaves in different leave layers. First, five commonly used vegetation indices (PSSR, PSND, CRI $I_{550}, C R I_{700}, B R I$ ) were performed to estimate the LCC. The PSSR got a better result with the higher estimation accuracy $\left(R^{2}=0.46\right)$. Second, the discrete wavelet transform algorithm (DWTA) was used to extract the wavelet feature vectors for estimating the LCC. The result showed that the most sensitive wavelet feature vector was in the sixth decomposition scale. The highest estimation accuracy $\left(R^{2}\right)$ was 0.86 for the lower leaf layer. Compared with those vegetation indices, the estimation accuracy $\left(R^{2}\right)$ improved $46.5 \% \sim 71.1 \%$, which indicated that the LCC of ginger in different leave layers can be accurately estimated by DWTA.
\end{abstract}

Keywords: Ginger · Leaf carotenoid concentration · Discrete wavelet transform algorithm · Wavelet feature vector

\section{Introduction}

Ginger (Zingiber officinale Roscoe), commonly known as its high agricultural and medical values, is cultivated widely in southwest, China [1-2]. Leaf carotenoid concentration (LCC) is an important bio-indicator of plant physiological state for their roles in photosynthesis. It can transfer the light energy to chlorophyll-a for converting to the light energy and protect the plant photosynthetic system[3-5]. Being able to estimate the LCC of ginger leaves could help in assessing the physiological status of crops (a) for detecting the leaf stress and senescence[6-7]. (b) for giving an estimation of the nutrient status indirectly[8], and (c) for providing an effective way to interpret the photosynthetic mechanism of plants and detect the water and fertilizer stress under the crop early growth stage[9]. Traditional method of LCC analysis often requires to take the plant into laboratory and measure it by extraction of ethanol. Although the experiment data is accurate, but it can't provide the changes of LCC in real time and consume a lot of energy. In recent years, hyperspectral techniques showed a great potential for estimating LCC over a range of spatial scales due to the spectral absorbance properties[10-12], but it seldom used to the industrial crop such as gingers. The photosynthetic pigment of plant includes chlorophyll, carotenoid and anthocyanin, however, the carotenoid is much samller compared with other pigments, especially the chlorophyll. So the estimation of LCC faces much challenges. Recently, wavelet transform as a new signal analysis tool has showed great potential in the analysis of hyperspectral data because it can amplify the weak signals and solve the overlap of

\footnotetext{
* Corresponding author . E-mail address: lqhwisdom@126.com
} 
spectral absorption features between chlorophyll and carotenoid[13]. Therefore, the aim of this paper include: (1) to compare the performance of vegetation indices and wavelet feature vector in estimating LCC (2) to identify the best decomposition scale in estimating LCC in different leave layers.

\section{Materials and methods}

\subsection{Experimental design and data collection}

The leaf scale spectral reflectance measurement was carried out during the 2015 growing season in the Special Seedling Experimental Base, in Chongqing $\left(29^{\circ} 11^{\prime} \mathrm{N}\right.$, $105^{\circ} 50^{\prime} \mathrm{E}$ ), China (Fig. 1). Two different ginger varieties were selected, and three nitrogen treatments with $0 \mathrm{~kg}$ (N0), 23kg (N1), and 46kg (N2) per plant were designed for this experiment, which represented three different nitrogen levels (non-fertilized, normal fertilization and excessive fertilization).

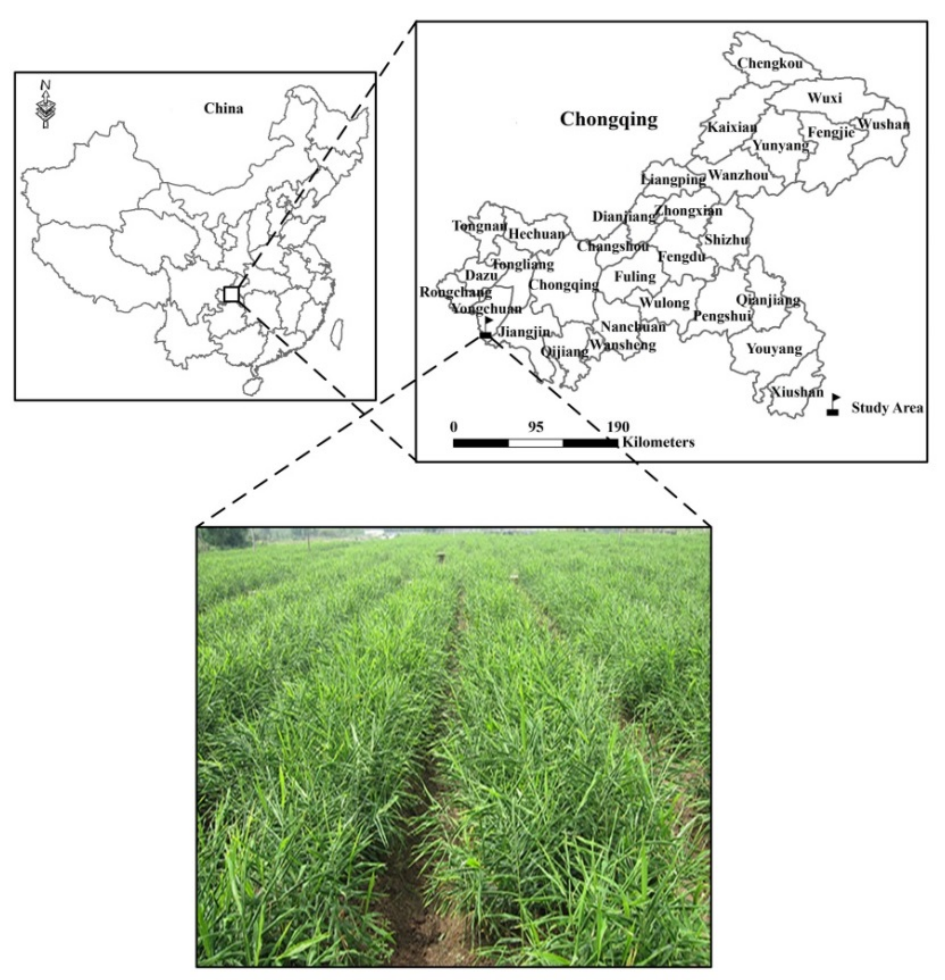

Fig. 1. Field experimental base of ginger

\subsection{Data acquisition}

The experimental data used in this study were collected from ginger in different leave layers at four crucial growth stages. Leaf spectral measurements were made by using an ASD Fieldspec FR spectroradiometer (Analytical Spectral Devices, Boulder, Colorado, USA) associated with a leaf clip. After that, the collected leaf samples were cut into pieces and extracted for $24 \mathrm{~h}$ in the dark at $22^{\circ}$ with $80 \%$ acetone. The absorbance was measured with a UV-VIS spectrophotometer at 440, 644, and 663nm. The LCC was determined using the equation provided by Lichtenthaler et al. [14]:

$$
\mathrm{LCC}=4.695 \times \mathrm{A}_{440}-0.268 \times \mathrm{Chl}_{\mathrm{a}+\mathrm{b}}
$$

Where $\mathrm{Chl}_{\mathrm{a}+\mathrm{b}}$ was chlorophyll concentration, $\mathrm{A}_{440}$ was the absorbance at $440 \mathrm{~nm}$.

\subsection{Calculation of vegetation indices}

To investigate the estimation performance of LCC, five commonly used 
vegetation indices were selected (Table 1 ).

Table 1. Vegetation indices used in this study, where $R_{\lambda}$ is the reflectance at waveband $\lambda(\mathrm{nm})$

\begin{tabular}{ccc}
\hline Vegetation indice & Formula & Reference \\
\hline$P S S R$ & $R_{800} / R_{470}$ & {$[15]$} \\
$P S N D$ & $\left(R_{800}-R_{470}\right) /\left(R_{800}+R_{470}\right)$ & {$[15]$} \\
$C R I_{550}$ & $1 / R_{510}-1 / R_{550}$ & {$[16]$} \\
$C R I_{700}$ & $1 / R_{510}-1 / R_{700}$ & {$[16]$} \\
$B R I$ & $R_{450} / R_{690}$ & {$[17]$} \\
\hline
\end{tabular}

\subsection{Extraction of the wavelet feature vector}

Wavelet transform is an effective mathematic tool that can decompose the original signal into different frequency components and each component is characterized with a resolution appropriate to its decomposion scale[18-20]. This method is performed using dilated and shifted versions of the mother wavelet, to produce a set of wavelet basis functions by the following equation:

$$
\psi_{a, b}=\frac{1}{\sqrt{a}} \psi\left(\frac{\lambda-b}{a}\right)
$$

Where $a$ represents the scaling factor (the wavelet's width) and $b$ represents the shifting factor (the wavelet's position), ensures that wavelets at every scale all have the same energy.

After that, the wavelet feature vector can be calculated using the following methods. The feature vector is calculated from:

$$
F_{j}=\sqrt{\frac{1}{K} \sum_{K=1}^{K}\left|W_{j, K}\right|^{2}}
$$

Where $K$ is the number of coefficients at the $j$ th decomposition level, $W_{j, k}$ is the $k t h$ coefficient at level $j$ and $p$ is the maximum number of decomposition levels.

\section{$3 \quad$ Results and Discussion}

\subsection{Estimating LCC by vegetation indices}

The selected vegetation indices were tested to estimate the LCC in different leave layers of ginger. Their correlation analysis results were shown in Table2. It turned out that the PSSR had the best result $\left(R^{2}=0.46, R M S E=2.63\right)$ for estimating the LCC of lower leaf layer, however, $C R I_{550}$ and $C R I_{700}$ showed a poor correlation with the LCC.

\begin{tabular}{|c|c|c|c|c|c|c|}
\hline \multirow{2}{*}{$\begin{array}{c}\text { Vegetation } \\
\text { indice }\end{array}$} & \multicolumn{2}{|c|}{ Upper layer } & \multicolumn{2}{|c|}{ Middle layer } & \multicolumn{2}{|c|}{ Lower layer } \\
\hline & $R^{2}$ & RMSE & $R^{2}$ & RMSE & $R^{2}$ & RMSE \\
\hline PSSR & $0.18^{\mathrm{a}}$ & 2.27 & $0.29^{a}$ & 2.82 & $0.46^{\mathrm{a}}$ & 2.63 \\
\hline PSND & $0.22^{\mathrm{a}}$ & 2.22 & $0.34^{\mathrm{a}}$ & 2.73 & $0.45^{\mathrm{a}}$ & 2.67 \\
\hline$C R I_{550}$ & 0.05 & 2.45 & $0.07^{\mathrm{C}}$ & 3.23 & 0.08 & 3.45 \\
\hline$C R I_{700}$ & 0.01 & 2.50 & 0.04 & 3.27 & $0.13^{C}$ & 3.35 \\
\hline$B R I$ & $0.24^{\mathrm{a}}$ & 2.19 & $0.31^{\mathrm{a}}$ & 2.76 & $0.29^{\mathrm{a}}$ & 3.02 \\
\hline
\end{tabular}

Table 2. Correlation analysis between the vegetation indices and LCC

Note: ${ }^{\mathrm{a}} p<0.001,{ }^{\mathrm{b}} p<0.01,{ }^{\mathrm{C}} p<0.05$

\subsection{Estimating LCC by wavelet feature vector}

As a widely used wavelet base function, Db5 was used to decompose the hyperspectral reflectance in different leaf layers. To display more clearer, only three 

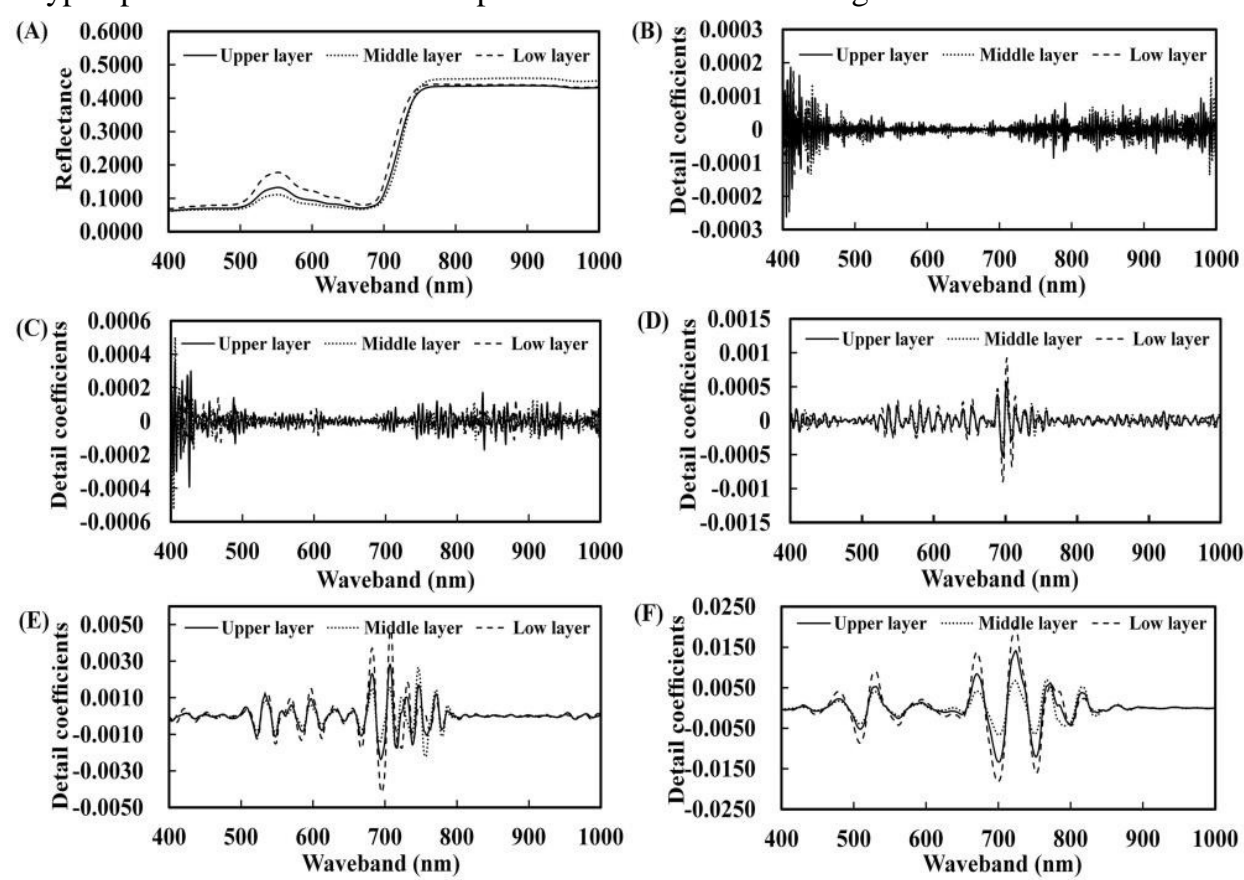

(G)
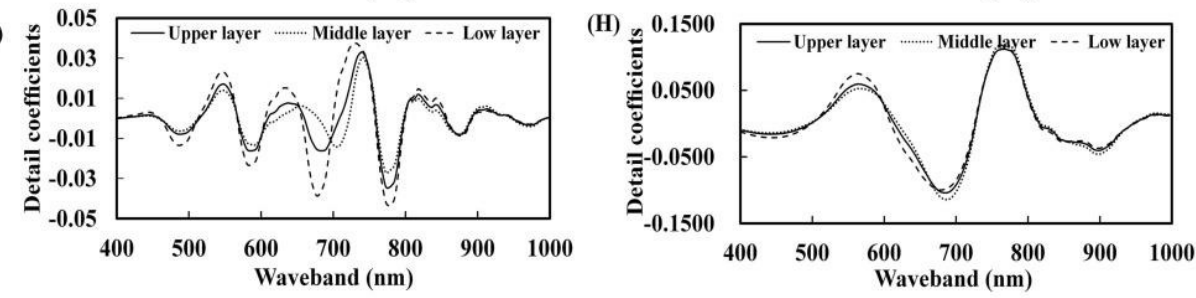

Fig. 2. Hyperspectral reflectance of three leaf layers decomposed by the DWTA. (A) Hyperspectral signal, (B) First level disassembled spectra, (C) Second level disassembled spectra, (D) Third level disassembled spectra, (E) Fourth level disassembled spectra, (F) Fifth level disassembled spectra, (G) Sixth level disassembled spectra, (H) Seventh level disassembled spectra

It showed that the decomposed spectral reflectance of the first, second and third decomposition scales are very intensive and sharp (Fig. 2 B, C and D), which represented the noise separation processes. With the decomposition scales increased, these detailed spectral signals became smooth and varied dramatically in the visible region, that is to say, the most useful information was successfully separated from the carotenoid. There has little change of the decomposed spectral reflectance as the decomposition scale varied from four to seven, that is, the decomposed spectral signals becomes stable, the wavelet feature vector should be extracted (Fig. 2H). Table3 summarized the performance of each wavelet feature vector for estimating the LCC. It showed that there has almost no correlation between LCC and wavelet feature vectors when the decomposition scales were at the first and second scales. This can be well explained by the signal noise at low decomposition scales. The best estimation accuracy of LCC appeared at sixth decomposion scale and the $R^{2}$ reached to 0.86 . Compared with the selected vegetation indices, the estimation accuracy $\left(R^{2}\right)$ improved $46.5 \% \sim 71.1 \%$ in different leave layers.

Table 3. Correlation analysis between the wavelet feature vector and LCC

\begin{tabular}{|c|c|c|c|c|c|c|}
\hline \multirow{2}{*}{$\begin{array}{l}\text { Decomposition } \\
\text { scale }\end{array}$} & \multicolumn{2}{|c|}{ Upper layer } & \multicolumn{2}{|c|}{ Middle layer } & \multicolumn{2}{|c|}{ Lower layer } \\
\hline & $R^{2}$ & RMSE & $R^{2}$ & RMSE & $R^{2}$ & $R M S E$ \\
\hline 1 & 0.01 & 2.40 & 0.03 & 3.25 & 0.29 & 2.65 \\
\hline 2 & $0.06^{c}$ & 2.34 & 0.00 & 3.30 & 0.00 & 3.16 \\
\hline 3 & $0.74^{\mathrm{a}}$ & 1.22 & $0.71^{\mathrm{a}}$ & 1.78 & $0.79^{\mathrm{a}}$ & 1.44 \\
\hline 4 & $0.72^{\mathrm{a}}$ & 1.28 & $0.62^{\mathrm{a}}$ & 2.04 & $0.71^{\mathrm{a}}$ & 1.69 \\
\hline 5 & $0.77^{\mathrm{a}}$ & 1.14 & $0.80^{\mathrm{a}}$ & 1.48 & $0.78^{a}$ & 1.46 \\
\hline
\end{tabular}




\begin{tabular}{ccccccc} 
& & & 5 \\
\hline 6 & $0.83^{\mathrm{a}}$ & 0.99 & $0.81^{\mathrm{a}}$ & 1.45 & $0.86^{\mathrm{a}}$ & 1.19 \\
7 & $0.35^{\mathrm{a}}$ & 1.94 & 0.33 & 2.70 & 0.02 & 3.13 \\
\hline
\end{tabular}

Note: ${ }^{\mathrm{a}} p<0.001,{ }^{\mathrm{b}} p<0.01,{ }^{\mathrm{c}} p<0.05$

\section{Conclusions}

This work aimed to develop a DWTA to estimate the LCC in different leave layers. Meanwhile, five commonly used vegetation indices were selected to compare the estimation accuracy with this method. The BRI, PSND and PSSR were the best vegetation indices for estimating LCC, but their highest estimation accuracy $\left(R^{2}\right)$ was only 0.46 . However, the wavelet feature vectors with decomposed scales from three to six were sensitive to LCC when the DWTA performed. The most sensitive wavelet feature vector for estimating the LCC was the sixth decomposition scale. The estimation accuracy $\left(R^{2}\right)$ improved $46.5 \% \sim 71.1 \%$ compared with vegetation indices. This study proves that DWTA is an effective method for estimating LCC of ginger in different layers, but using it at canopy scale will be a challenge due to the effect of LAI and soil background. Therefore, the successful use of canopy hyperspectral reflectance to estimate LCC will be an interesting extension of this work.

\section{Acknowledgments}

This work was supported by National Natural Science Foundation of China (No.41401419); A Project Supported by Scientific Research Fund of Chongqing Municipal Education Commission (KJQN201801335).

\section{References}

1. Grzanna, R., Lindmark, L., Frondoza, C. G. Ginger-an herbal medicinal product with broad anti-inflammatory actions. J. Med. Food. 8(2), 125-132 (2005)

2. Marx, W., Ried, K., McCarthy, A. L., Vitetta, L., Sali, A., McKavanagh. D., Isenring, L. Ginger-Mechanism of action in chemotherapy-induced nausea and vomiting: A review. Crit. Rev. Food Sci. 57(1), 141-146 (2017)

3. Frank, H. A. and Cogdell, R. J. Carotenoids in photosynthesis. Photochem. Photobio. 63(3), 257-264 (1996)

4. Hura, K., Hura, T., Grzesiak, M. Function of the photosynthetic apparatus of oilseed winter rape under elicitation by Phoma lingam phytotoxins in relation to carotenoid and phenolic levels . Acta. Physiol. Plant. 36(2), 295-305(2014)

5. García-Cañedo, J. C., Cristiani-Urbina., E., Flores-Ortiz, C. M., Ponce-Noyola, T., Esparza-García, F., Cañizares-Villanueva, R. O. Batch and fed-batch culture of Scenedesmus incrassatulus: Effect over biomass, carotenoid profile and concentration, photosynthetic efficiency and non-photochemical quenching. Algal. Res. 13, 41-52(2016)

6. Wang, H. Y., Yang A., Zhang G. M., Ma, B. Y., Meng, F., Peng, M., Wang, H. C. Enhancement of carotenoid and bacterio chlorophyll by high salinity stress in photosynthetic bacteria. Int. Biodeter. Biodegr. 121, 91-96(2017)

7. Shah, S. H., Houborg, R., McCabe, M. F. Response of chlorophyll, carotenoid and SPAD502 measurement to salinity and nutrient stress in wheat (Triticum aestivum L.). Agron. J. 7(3), 61. (2017)

8. Chenard, C. H., Kopsell, D. A., Kopsell, D. E. Nitrogen concentration affects nutrient and carotenoid accumulation in parsley. J. Plant Nutr. 28, 285-297 (2005)

9. Demmig-Adams, B. and Adams III, W. W. The role of xanthophyll cycle carotenoids in the protection of photosynthesis. Trends Plant. Sci. 1(1), 21-26 (1996)

10. Kong, W. P., Huang, W. J., Zhou, X. F., Song, X. Y., Casa, R. Estimation of carotenoid content at the canopy scale using the carotenoid triangle ratio index from in situ and simulated hyperspectral data. J. Appl. Remote Sens. 10(2), 026035 (2016)

11.Kong, W. P., Huang, W. J., Liu J. G., Chen, P. F., Qin, Q. M., Ye, H. C., Peng, D. L., Dong, Y. Y., Mortimer, A. H. Estimation of canopy carotenoid content of winter wheat 
using multi-angle hyperspectral data. Adv. Space Res. 60(9), 1988-2000(2018)

12. Sonobe, R., Miura, Y., Sano, T., Horie, H. Estimating leaf carotenoid contents of shadegrown tea using hyperspectral indices and PROSPECT-D inversion. Int. J. Remote Sens. 39(5): 1306-1320(2018)

13. Garrity, S. R., Eitel, J. U. H., Vierling, L. A. Disentangling the relationships between plant pigments and the photochemical reflectance index reveals a new approach for remote estimation of carotenoid content. Remote Sens. Environ. 115, 628-635 (2011)

14. Lichtenthaler, H. K. Chlorophylls and carotenoids: pigments of photosynthetic biomembranes. Method Enzymol. 148(34), 350-382 (1987)

15. Blackburn, G. A. Quantifying chlorophylls and caroteniods at leaf and canopy scales: an evaluation of some hyperspectral approaches. Remote Sens. Environ. 31(2), 221-230 (1998)

16. Gitelson, A. A., Zur, Y., Chivkunova, O. B., Merzlyak, M. N. Assessing carotenoid content in plant leaves with reflectance spectroscopy. Photochem. Photobiol. 75(3), 272281 (2002)

17.Zarco-Tejada, P. J., Berjón, A., López-Lozano, R., Miller, J. R., Martín, P., Cachorro, V., González, M. R, de Frutos, A. Assessing vineyard condition with hyperspectral indices: leaf and canopy reflectance simulation in a row-structured discontinuous canopy. Remote Sens. Environ. 99(3), 271-287 (2005)

18. Prabhakar, T. V. N., Geetha, P. Two-dimensional empirical wavelet transform based supervised hyperspectral image classification. Isprs. J. Photogramm. 133, 37-45(2017)

19. Huang, S. Q., Liu, Z. G., Wang, Y. T., Wang, R. R. Wide-stripe noise removal method of hyperspectral image based on fusion of wavelet transform and local interpolation. Opt. Rev. 24, 177-187(2017)

20.Zhang, Y. Z., Wu, H., Jiang, X. G., Jiang, Y. Z., Liu, Z. X., Nerry, F. Land surface temperature and emissivity retrieval from field-measured hyperspectral thermal infrared data using wavelet transform. Remote Sens. 9(5), 454(2017) 